\title{
Reverse sequestration in a case of sickle crisis
}

\author{
Edwin SH Lee, Patrick CM Chu
}

\begin{abstract}
Summary
A patient with homozygous sickle cell disease presented with sickle crisis complicated by hepatic and pulmonary sequestration and required intensive therapy. During the recovery phrase she developed a rapid rise of haemoglobin concentration, unrelated to blood transfusion, followed by hypertension, congestive cardiac failure and catastrophic intracerebral haemorrhage. This serious haemodynamic disturbance was considered to be caused by a reversal of the sequestration process. Careful monitoring of a sickle cell patient's blood pressure, blood counts, haematocrits, haemoglobin $S$ level and plasma viscocity, even after the end of a sequestration crisis, is recommended.
\end{abstract}

Keywords: sickle cell crisis, transfusion, sequestration

Red cell sequestration in the liver or lung is common in a patient with homozygous sickle cell disease. In a young patient without hyposplenism, the spleen may also be involved. Sequestration manifests clinically with a rapid drop of haemoglobin and biochemical changes of haemolysis, as well as acute enlargement and malfunction of the organ involved. Treatment is mainly supportive, consisting of transfusion, careful monitoring of fluid balance, oxygen and pain relief. ${ }^{1}$ Successful treatment is often reflected by a gradual reduction in transfusion requirement and reduction in size of the affected organ.

We present a case of a young patient who had an unusual clinical course after developing a sickle crisis with hepatic and pulmonary sequestration.

\section{Case history}

A 33-year-old African woman with homozygous sickle cell disease presented with acute onset wrist and back pain, right upper abdominal discomfort, fever, rigor and vomiting. In the past she had had frequent sickle crises, often complicated by hepatic sequestrations. In the steady state she had a 4-6 cm hepatomegaly, chronic leg ulcers and haemoglobin levels around $5 \mathrm{~g} / \mathrm{dl}$. Her multiple red cell antibodies $[\mathrm{C}, \mathrm{N}, \mathrm{Fy}(\mathrm{a}), \mathrm{Jk}(\mathrm{b}), \mathrm{Js}(\mathrm{a}), \mathrm{s}]$ made cross-matching technically difficult and exchange transfusion impractical. Several previous transfusions with the least incompatible blood available for life-threatening crises had to be covered by high-dose hydrocortisone and immunoglobu- lin. She was on long-term prophylactic penicillin-V and folic acid.

On admission she was pyrexic, tachycardic and jaundiced with a blood pressure of 120/50 $\mathrm{mmHg}$. Liver was palpable at $5 \mathrm{~cm}$. Haemoglobin was $5.6 \mathrm{~g} / \mathrm{dl}$. Liver enzymes were slightly more elevated than her normal levels. Chest radiograph, arterial blood gas and biochemistry were normal. Bacteriological cultures were subsequently found to be sterile.

She initially responded to the empirical treatment of co-amoxyclav, intravenous rehydration and analgesics. On the sixth day after admission, she became pyrexic, tachycardic and acutely confused. Haemoglobin dropped to $3.5 \mathrm{~g} / \mathrm{dl}$, and she developed a neutrophil leucocytosis. Her antibiotic was changed to ceftazidine and two units of least incompatible blood was given slowly under high-dose hydrocortisone cover over the next two days. Her haemoglobin was restored to $4.9 \mathrm{~g} / \mathrm{dl}$.

Gradually over the next five days she developed features of hepatic sequestration, with tender hepatomegaly to $7 \mathrm{~cm}$ and hyperbilirubinaemia. On the thirteenth day after admission, she developed further pain in her chest and back, became dyspnoeic, and her haemoglobin fell to $2.2 \mathrm{~g} / \mathrm{dl}$. Her liver was then palpable at $12 \mathrm{~cm}$. Chest X-ray showed patchy shadowing suggestive of pulmonary sequestration. Two further units of blood were given. Because of her overall deterioration and hypoxaemia, she was admitted to the intensive therapy unit for assisted ventilation on the fifteenth day after admission. After further transfusions her haemoglobin rose to $5.1 \mathrm{~g} / \mathrm{dl}$ on the seventeenth day. No further transfusions were given.

Her haemoglobin rose to $7.2 \mathrm{~g} / \mathrm{dl}$ on the eighteenth day after admission. Her calculated plasma osmolality was within the normal range, and her fluid balance was normal, suggesting that the rise in haemoglobin was genuine rather than secondary to haemoconcentration. An attempt to wean her off the ventilator was unsuccessful on the next day, and she remained deeply unconscious, with a divergent squint, bilateral up-going plantars and arm flexion to painful stimuli. Later that evening her systolic blood pressure rose quickly to $200 \mathrm{mmHg}$ and she developed signs of pulmonary oedema from left ventricular failure with a reduction of her oxygen saturation once again. An urgent computed tomography brain scan done on the following day demonstrated haemorrhages into the internal capsule, thalamus and surrounding white matter. Surprisingly her haemoglobin was found to be $12.3 \mathrm{~g} / \mathrm{dl}$ with a haematocrit of
University Department
of Haematology, Royal Liverpool University Liverpool, L7 8XP, UK ESH Lee

Accepted 13 November 1995 


\section{Features of reverse sequestration in sickle crisis}

- sudden onset hypertension

- acute congestive cardiac failure

- acute neurological features of cerebral infarct or intracerebral haemorrhage

$34.5 \%$ that day. The patient's family agreed with the medical decision to withhold further active treatment and she died peacefully that evening. Permission for a post mortem was declined.

\section{Discussion}

Figure 1 shows the trend of haemoglobin and haematocrit during the patient's final admission. While the earlier part of her admission was typical of a sickle crisis followed by hepatic and pulmonary sequestration, the dramatic rises of her haemoglobin and haematocrit during the last three days of this episode were very unusual. With the last blood transfusion of one unit being four days before the rise, this phenomenon was unlikely to have been due to over-transfusion.

The brisk rise of $5 \mathrm{~g} / \mathrm{dl}$ of haemoglobin over 24 hours was too rapid to be due to haematopoiesis alone. We therefore suggest that there was a reversal of the sequestration process, possibly resulting from the relief of sinusoidal obstruction, to allow sequestrated, reversibly sickled and transfused, red cells to re-enter the circulation, a process that, to our knowledge, has not previously been reported.

The phenomenon of reverse sequestration in this case resulted in a very sudden volume load, complicated by acute onset hypertension, congestive cardiac failure and intracranial haemorrhage. The pathophysiology of such a process was likely to mirror that seen after additive blood transfusions in patients with sickle cell anaemia. Despite a low haemoglobin level, these patients were known to have normal or near normal whole blood viscocity due to the presence of poorly deformable sickle cells. Additive blood transfusions would significantly increase the total circulating blood volume, as well as viscocity, and have been aetiologically related to intracerebral infarcts ${ }^{2-4}$ and haemorrhages. ${ }^{5}$ In fact, neurological events have also been reported after even partial exchange transfusion for priapism to achieve haemoglobin $S$ levels at less than $30 \%,{ }^{6}$ emphasising the risk of even small

1 Harrison JFMcK, Davies SC. Acute problems in sickle cell disease. Hospital Update 1992; Oct: 709-51.

2 Ohene-Fempong $\mathrm{K}$. Stroke in sickle cell disease: demographic clinical and therapeutic considerations. Semin Haematol 1991; 28: 213-9.

3 Serjeant GR. The nervous system. In: Sickle cell disease, 2nd edn. Oxford University Press, 1992; pp 292-314.

4 Hindmarsh PC, Brozovic M, Brook CGD, Davies SC. Incidence of overt and covert neurological damage in children with sickle cell disease. Postgrad Med $\mathcal{7} 1987$; 63: 751-3.

\section{Learning points}

- additive or partial exchange transfusion in a sickle crisis may be associated with an increased risk of neurological complications. Transfusions, if required, should be done on an exchange basis

- at the end of a sickle sequestration crisis, sequestrated red cells may re-enter the circulation leading to acute volume overload

- monitoring of blood pressure, blood counts, haematocrit, haemoglobin levels and plasma viscocity during and after a crisis may be helpful in the detection of the reversal of the sequestration process and allow early intervention

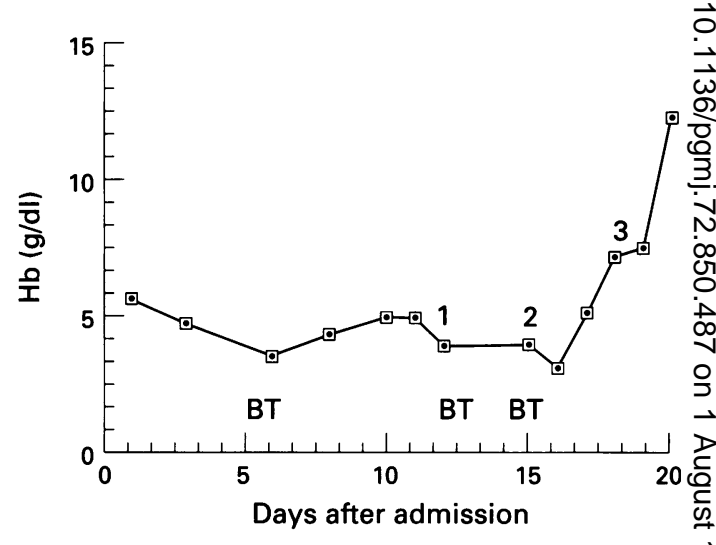

Figure Haemoglobin levels. Key: 1, acute hepatic and pulmonary sequestration; 2 , admission to intensive care unit; 3, neurological deterioration; BT, blood transfusion

increases in whole blood viscocity. Reversal of $\stackrel{\square}{\triangle}$ the sequestration process, even when minimal, $\overrightarrow{\bar{o}}$ undoubtedly increases the whole blood visco- $\exists$ city and may have catastrophic consequences.

We would like to make two additional recommendations regarding the treatment of sickle cell anaemia patients having a sequestration crisis:

- additive or partial exchange transfusion in a sickle crisis may be associated with an increased risk of neurological complica- 0 tions. Transfusions, if required, should be done on an exchange basis

- monitoring of blood pressure, blood counts, haematocrit, haemoglobin level 0 and plasma viscocity during and after a $N$ crisis may be helpful in the detection of the reversal of the sequestration process and 0 allow early intervention.

5 Royal JE, Seeler RA. Hypertension, convulsions, and cerebral haemorrhage in sickle-cell anaemia patients after blood transfusions. Lancet 1978; ii: 1207.

6 Rackoff WR, Ohene-Frempong K, Month S, Stott JP, Neahring B, Cohen $R$. Neurologic events after partial exchange transfusion in sickle cell disease. $f$ Paediatrics 1992; 120: 882-5. 